\title{
Alice no País da LIBRAS: uma experiência/ reflexão pedagógica de letramento para educandos surdos
}

\section{Alice in LIBRAS Country: an experience/pedagogical reflection of literacy for deaf students}

https://doi.org/10.34112/2317-0972a2018v36n74p91-108

\section{Lúcia Peixoto Cherem ${ }^{2}$ \\ Suellym Fernanda OpOLz}

RESUMO: Ler e escrever pode ser fascinante quando a aprendizagem é ambientada por temáticas que despertam o interesse e estimulam o imaginário infantil. E para os alunos surdos, que aprendem a ler pela via lexical, a prática de letramento precisa ser instigante, conduzindo e desafiando o educando ao uso funcional da leitura e da escrita e à descoberta de um mundo de conhecimentos, tal como a menina Alice, de Alice no País das Maravilhas, da obra de Lewis Carroll. Ou seja: o processo de letramento precisa ser significativo, com temas que despertem o interesse das crianças para uma efetiva construção de sua aprendizagem. Assim, este projeto de letramento pela via direta - realizado entre agosto e setembro 2016 com uma turma do $3^{\circ}$ ano do ensino fundamental de uma escola de educação bilíngue para surdos - foi contextualizado na obra Alice no País das Maravilhas, tendo por objetivo estimular a leitura e desenvolver a escrita. Tal projeto mostrou-se efetivo, oportunizando aos alunos surdos a construção e assimilação de significados para palavras, frases e textos lidos, e desenvolvendo o uso funcional da leitura e da escrita em português brasileiro - na perspectiva de uma segunda língua, já que a língua natural dos educandos surdos é a LIBRAS. Então, utilizando a LIBRAS como ferramenta de mediação e pautando-se

1. Narrativa adaptada da obra original de Lewis Caroll pela Profa. Suellym Opolz para o contexto da LIBRAS e da cultura surda.

2. Universidade Federal do Paraná, Curitiba, PR, Brasil.

3. Prefeitura Municipal de São José dos Pinhais, São Jose dos Pinhais, PR, Brasil . 
Alice no País da LIBRAS: uma experiência/reflexão pedagógica de letramento...

na interdisciplinaridade, este projeto de letramento foi estruturado em etapas de leitura, interpretação, produção e narrativa, promovendo atividades de análise linguística, leitura ideovisual de variados gêneros textuais e produção escrita de textos coletivos e individuais - contextualizadas no enredo da obra de Lewis Carroll.

PALAVRAS-ChAVE: Letramento; educação bilíngue; prática pedagógica.

ABSTRACT: Reading and writing can be fascinating when learning is acclimated by themes that arouse interest and stimulate children's imagination. And for deaf students who learn to read through the lexical way, literacy practice must be thought provoking, challenging to learners. and must lead them to the functional use of reading and writing, and to the discovery of a world of knowledge, such as little girl Alice in Alice in Wonderland, written by Lewis Carroll. The literacy process must be meaningful, with themes that arouse children's interest for an effective construction of their learning. Thus, this literacy project - that took place between August and September of 2016 in a third-year group of elementary bilingual school for deaf students - had as context the literary work of Alice in Wonderland to stimulate reading and to develop writing. This project proved to be effective, allowing the deaf students to construct and assimilate meanings for words, phrases and texts that had been read, and to develop the functional use of reading and writing in Brazilian Portuguese - in the bilingual perspective of a second language, since the natural language of the deaf students is LIBRAS. Then, using LIBRAS as a tool of mediation and based on interdisciplinarity, this literacy project was structured in stages of reading, interpretation, production and narrative, promoting activities of linguistic analysis, ideovisual reading of various textual genres and written production of collective and individual texts - contextualized in the plot of the literary work written by Lewis Carroll.

KEYWORDS: Literacy; bilingual education; pedagogical practice.

\section{Planejamento}

Acreditamos que aprender a ler e escrever pode ser fascinante quando se torna, para o educando, um processo significativo que estimule a organização de seu processo de pensamento e amplie seu conhecimento de mundo. Diante desta perspectiva, considera-se importante contextualizar o processo de aquisição da leitura e da escrita para crianças em temáticas que despertem o interesse infantil, que instiguem sua curiosidade e possibilitem uma construção efetiva de sua aprendizagem, sendo que "letramento é pois, o resultado da ação de ensinar ou aprender a ler e a escrever; $o$ 
estado ou a condição que adquire um grupo social ou indivíduo como consequência de ter se apropriado da escrita" (SOARES, 1999, p. 18).

Assim, no terceiro trimestre de 2016, ao pensar em uma temática de aula para os alunos do $3^{\circ}$ ano do Ensino Fundamental, com idades entre 7 e 9 anos, optou-se pelo clássico literário Alice no País das Maravilhas, de Lewis Carroll. Isto porque o enredo da obra é repleto de elementos e personagens fantásticos, que estimulam a criatividade e a expressão linguística dos alunos, pois envolvem o lúdico e o simbólico no processo de ensino e aprendizagem de letramento, despertando o interesse pela leitura.

Além disso, percebeu-se que tal narrativa permite construir uma sequência didática pautada na interdisciplinaridade, destacando conteúdos tanto na área de língua portuguesa (leitura, interpretação e análise linguística), como na área de história (orientação temporal), na área de matemática (conteúdo de medidas de tempo/horas) e na área das artes (teatro/expressão corporal). Então, realizou-se uma leitura e análise do currículo municipal para o $3^{\circ}$ bimestre do $3^{\circ}$ ano do Ensino Fundamental e foram sistematizadas aulas para um projeto de letramento, considerando uma sequência didática. Registrados os planos de aula, o projeto foi analisado pela equipe pedagógica e, com seu apoio, realizado.

Tal projeto, tendo por objetivo geral estimular a leitura e desenvolver a escrita mediante letramento, considerou como objetivos específicos estruturar a sequência lógica de ideias; assimilar novos vocabulários em português brasileiro, interpretar informações, bem como ideias expressas em diferentes gêneros textuais; e reconhecer a função social da leitura e da escrita (código escrito). Como o enredo da obra Alice no País das Maravilhas retrata um coelho preocupado com o tempo/horário, foi oportuno considerar, também, como objetivos específicos, desenvolver a compreensão de medidas de tempo e realizar a leitura de horas e minutos, relacionando aos períodos do dia e à rotina dos alunos. Também se destacou o fato de a história ter sido escrita e ambientada no século XIX, o que permitiu aos alunos refletir sobre a passagem do tempo, estabelecendo comparações entre o passado e o presente.

Outro fato pontuado na estruturação deste projeto foi a possibilidade de desenvolver a expressão corporal através de encenação/dramatização na etapa final, tendo em vista que a temática poderia estimular o jogo simbólico das crianças e instigar a representação teatral. Neste momento, obtivemos apoio de outros professores, bem como da equipe pedagógica, para filmagem, composição de cenários e figuração. 
Alice no País da LIBRAS: uma experiência/reflexão pedagógica de letramento...

Tendo em vista tal encaminhamento metodológico, ressalta-se que este projeto foi baseado na perspectiva do autor e pesquisador francês Jean Foucambert sobre letramento pela via direta, que leva em conta o acesso direto aos textos - literários ou não - desde o início da aprendizagem da leitura, de forma a perceber o conhecimento de mundo dos alunos quando operam a construção do sentido sobre a leitura e escrita. Assim, o trabalho pela via direta deve ser realizado de forma aprofundada e sistemática ao longo dos encontros, permitindo a reflexão linguística para a compreensão do funcionamento da linguagem.

Deste modo, considerando um total de 12 encontros e tendo por metodologia a concepção de letramento pela via direta, o projeto foi delimitado em cinco etapas:

1. Narração e Leitura

2. Interpretação

3. Pesquisa

4. Produção

5. Narração/Dramatização

Ressalta-se que esta experiência de letramento pela via direta na educação de surdos demonstrou-se efetiva, bem como inovadora, uma vez que permitiu ao educando a construção e assimilação de significados para palavras, frases e textos lidos num contexto lexical, o que auxilia na transformação dos alunos em efetivos leitores.

Este foi o principal objetivo desta prática pedagógica, que se baseou nas concepções do letramento pela via direta adaptadas ao contexto da surdez, que questionam práticas que descartam teorias de leitura que levam em conta a antecipação da sintaxe do português brasileiro nas atividades propostas. E no que se refere particularmente aos educandos surdos, o letramento pela via direta mostrou-se um caminho efetivo na busca por uma educação bilíngue significativa, utilizando como ferramenta de mediação a Língua Brasileira de Sinais (LIBRAS), a primeira língua do educando surdo. Conforme destaca Fernandes (2008, p. 12):

Conscientizemo-nos que a constituição dos sentidos na escrita pelos estudantes surdos decorrerá de processos simbólicos visuais e não auditivos. Aprender o português, nesse sentido, demanda um processo de natureza cognitiva (para o surdo) e metodológica (para o professor) que difere totalmente dos princípios que a literatura na área do ensino de português como língua materna tem sistematizado. 
Desse modo, respeitam-se as necessidades e especificidades de aprendizagem da criança surda e estimula-se o desenvolvimento de sua autonomia para explorar o mundo da leitura, um mundo de descobertas, de significados e de transformações, ou seja, de construção de conhecimento, assim como ocorreu com a menina Alice ao conhecer $O$ País das Maravilhas.

\section{Diagnóstico}

A escola em que ocorreu este projeto de letramento, em 2016, é uma escola pública de Educação Básica, na modalidade de Educação Especial Bilíngue para Surdos, no município de São José dos Pinhais, no Paraná. A escola atende alunos surdos em etapas de aprendizagem da Educação Infantil até às séries iniciais do Ensino Fundamental ( $1^{\circ}$ ao $5^{\circ}$ anos), utilizando como língua de mediação, em sua prática pedagógica, a Língua Brasileira de Sinais que, por ser uma língua visual/ espacial, é naturalmente adquirida pelos educandos surdos quando estes estão inseridos num contexto escolar bilíngue.

Sendo assim, a LIBRAS se manifesta como a primeira língua ( $\left.\mathrm{L}_{1}\right)$ e é a ferramenta de ensino/aprendizagem da escola. Ou seja, os conteúdos curriculares e o contexto sócio-educacional dos alunos, bem como toda prática pedagógica, são sistematizados e significados através da LIBRAS. Isto porque:

(...) A surdez pode ser vista dentro de um campo de ações construídas pela linguagem. É a linguagem que permite a criação de um sistema de significações para representar coisas e negociar sentidos sobre elas. É sobre os sentidos que damos às coisas que construímos nossas experiências cotidianas e nossas interpretações sobre nós e sobre os outros. (LOPES, 2007, p. 16)

Neste cenário, tendo a LIBRAS como ferramenta de mediação, o aluno surdo é inserido no mundo da leitura e da escrita em português brasileiro que será a sua segunda língua $\left(\mathrm{L}_{2}\right)$ na modalidade escrita, através da metodologia de letramento que objetiva estimular o aluno surdo ao uso social e funcional da leitura e escrita, considerando que:

Letramento é o estado daquele que não só sabe ler e escrever, mas que também faz uso competente e frequente da leitura e da escrita, e que, ao se tornar letrado, muda seu 
Alice no País da LIBRAS: uma experiência/reflexão pedagógica de letramento...

lugar social, seu modo de viver na sociedade, sua inserção na cultura. (QUADROS; SCHMIEDT, 2006, p. 17)

Evidencia-se, no entanto, que o processo de letramento só se torna efetivo e significativo para o educando surdo quando abordado, desde a educação infantil, pela via lexical, e não fonética, pois os alunos surdos não têm o processamento auditivo necessário para apropriação do sistema de escrita alfabética.

Porém, ao usar a LIBRAS como ponto de partida, e não como ferramenta de mediação para o letramento em si, subestimando o conhecimento prévio do educando, tende-se a aplicar uma metodologia descontextualizada, que tem por objetivo apenas a relação sinal/palavra, figura/palavra, induzindo o aluno surdo a priorizar a leitura de imagens em detrimento do código escrito. Diante de tal prática, o aluno não é desafiado, instigado a ler, já que não percebe a necessidade e a funcionalidade da leitura do português brasileiro na modalidade escrita. Além disso,

A falta de atividades significativas com a escrita impede que os surdos percebam sua função social e as diferenças entre a língua majoritária e a língua de sinais, ou seja, que cada modalidade de língua possui regras e recursos específicos. (GUARINELLO, 2007, p. 55)

Conforme ressalta Carvalho (2013, p. 67) "não se ensina a gostar de ler por decreto, ou por imposição, nem se forma letrados por meio de exercícios de leitura e gramática rigidamente controlados. Para formar indivíduos letrados, a escola tem que desenvolver um trabalho gradual e contínuo".

Então, para a criança surda, o desenvolvimento da aprendizagem da leitura e da escrita ocorrerá na forma de uma segunda língua, por uma via direta - da mesma maneira que uma criança brasileira aprenderá uma língua estrangeira, por exemplo. Isto porque a linguagem escrita é um fator cultural - diferentemente da linguagem oral que, além de cultural, é também um fator biológico. Daí a perspectiva de uma educação bilíngue - LIBRAS/PORTUGUÊS - pois:

Sendo a lingua(gem) uma função cognitiva privilegiada por sua natureza auto-reflexiva e mediadora, que constitui relação com o mundo social, deve-se considerar como essencial na educação de surdos a transformação de uma política pedagógica crítica por meio do ensino bilíngue. (SILVA, 2001, p. 22) 
E é nesta perspectiva que este projeto de letramento se baseia. Consideramos que os alunos surdos possuem habilidades e capacidades para aprender uma segunda língua, tornando-se leitores funcionais, estabelecendo conceitos e significados ao que se está lendo e escrevendo, usando a linguagem escrita como função social, isto porque: "As situações funcionais são, para a leitura, todas as situações que criam a necessidade de se recorrer a um contexto escrito, sob qualquer forma" (FOUCAMBERT, 2008, p. 155).

Diante deste contexto, percebemos o quanto era necessário abordar o letramento por uma temática que despertasse o interesse dos alunos pelo uso funcional do português brasileiro - na modalidade escrita - instigando-os a descobrir os significados de palavras, textos, mensagens. É evidente que nem todos os alunos apresentam um mesmo ritmo de aprendizagem, de assimilação de vocabulário, de interpretação. Entretanto, percebemos em uma turma - formada por cinco alunos surdos, com idade entre 8 a 9 anos, e fluentes em LIBRAS - um crescente entusiasmo pela descoberta da leitura.

\section{Desenvolvimento}

Nesta experiência prática, projeto de letramento, as aulas estavam contextualizadas no tema Alice no País das Maravilhas, de Lewis Carrol, com a intenção de despertar o interesse pelo universo do enredo, estimulando a leitura e o desenvolvimento da escrita em português brasileiro junto aos educandos surdos e conduzindo-os à metalinguagem e à análise linguística, fazendo transposição do significado das mensagens lidas e escritas da LIBRAS para o português brasileiro e do português brasileiro para a LIBRAS.

Além disso, foi oportuno aprofundar a consciência e a orientação temporal dos alunos, discriminando o período histórico do enredo, bem como estimular a localização e identificação de continente e país em que a narrativa acontece - no caso a Inglaterra do século XIX - observando mapas, globo terrestre e reconhecendo as configurações culturais que caracterizam tal país e seu continente, ampliando o conhecimento de mundo dos alunos que se mostraram muito interessados nessa dinâmica. Ainda no que corresponde à área da história, foi possível desenvolver a orientação temporal, relacionando datas a períodos históricos, comparando passado e presente. Como se percebe, o projeto pautou-se na interdisciplinaridade, interligando/integrando conteúdos curriculares das Diretrizes Curriculares Municipais para $03^{\circ}$ ano do Ensino Fundamental e utilizando, como ferramenta de mediação, 
Alice no País da LIBRAS: uma experiência/reflexão pedagógica de letramento...

a LIBRAS. O projeto de letramento foi planejado e aplicado durante um bimestre, num total de 12 aulas, com média de três horas semanais. Delimitou-se o projeto em cinco etapas: narrativa e leitura, interpretação, pesquisa, produção e dramatização, conforme detalhado a seguir.

\section{A NARRATIVA E A LEITURA}

O ponto de partida para o projeto foi a narração, em LIBRAS, da história Alice no País das Maravilhas. O conto foi narrado para os alunos a partir do uso da LIBRAS e da expressão corporal/dramatização, esta como componente complementar, evidenciando o perfil de cada um dos personagens da história - atividade em que se percebeu que a expressão facial e a dramatização da professora captaram total atenção das crianças. Tal percepção ilustra o quanto é importante a contextualização das aulas em temáticas que despertem o imaginário infantil. Ressaltamos que, nesta primeira atividade, não foi utilizado nenhum recurso de imagem (desenho/ gravura), pois um dos objetivos era perceber o nível de assimilação das informações que os alunos teriam através da LIBRAS e a construção de imagens mentais, dimensionando a estrutura de pensamento e expressando o conhecimento de mundo. Considera-se que esta atividade pode estar relacionada à sondagem, visto que através dela foi possível perceber o nível de assimilação da linguagem receptiva e delinear o conhecimento prévio das crianças.

Assim, na mesma aula - após a narrativa realizada pela professora - foi solicitado aos alunos que fizessem um desenho em quadrinhos, relativo à narrativa, destacando a sequência lógica da história. A maioria dos alunos conseguiu realizar tal atividade, sendo que alguns não demonstraram autonomia para representar a narrativa, através do desenho, solicitando auxílio. Porém, nesta atividade não houve mediação porque a intenção era de que os alunos expressassem - de forma autônoma - o que entenderam da narrativa. Foi interessante perceber que cada aluno expressou uma perspectiva diferente da história, destacando o cenário que mais despertou sua atenção.

Numa segunda aula, as crianças foram instigadas a expor informações sobre a história. Foi-lhes perguntado (em LIBRAS) quais personagens havia na história narrada anteriormente e assim elas foram comentando e sinalizando cada um dos personagens: Alice, Chapeleiro Maluco, Gato, Coelho Branco, Lebre, Lagarta, Rainha de Copas. Todos os alunos se mostraram participativos, interagindo com os questionamentos feitos sobre a narrativa. Em seguida, foram questionados sobre o lugar em 
que se passava a história e todos responderam: "No País das Maravilhas". O aluno W lembrou-se da Inglaterra e outro aluno, V, lembrou-se da casa do Chapeleiro e do castelo da Rainha de Copas.

Então a professora regente, tendo o papel de escriba, auxiliou os alunos a registrar em português brasileiro tais informações, destacando na lousa as palavras-chave, dentre as quais sobressaíram: PAÍS DAS MARAVILHAS e ALICE. A professora destacou com a cor laranja substantivos próprios, referentes aos personagens, com a cor verde os lugares e com a vermelha os marcadores cronológicos (anos). Também foram realizados outros questionamentos que instigaram as crianças a realizar uma interpretação lógica da obra de Lewis Carroll, como: Por que o Coelho estava com pressa? Por que Alice cresceu muito? Por que o tamanho da Alice diminuiu? Tais questionamentos não foram respondidos de forma imediata pelas crianças, mas o retorno a partes concretas da narrativa conduziu os alunos a uma conexão lógica, estimulando a correspondência entre causas e efeitos, que é uma das principais dificuldades no processo de leitura por parte das crianças surdas.

Em seguida, tendo por base as palavras/ideias-chave, foi produzido um texto coletivo (escrito na lousa). Depois, solicitou-se que os alunos fizessem a cópia desse texto no caderno de Linguagem, tendo por objetivo conhecer a estruturação textual (paragrafação, sequência de ideias) e elementos do texto (pontuação), além da orientação espacial. Finalizada a cópia, as crianças foram orientadas a circular/ destacar, no texto, as palavras que já conheciam, utilizando uma cor para cada classe de palavras: laranja para nomes próprios, azul para verbos, verde para lugares, rosa para substantivos comuns e amarelo para pontuação. Por meio das palavras em destaque, as crianças foram estimuladas a ler o texto no quadro negro, com o intento de promover desafios e instigá-los para a leitura.

$\mathrm{Na}$ terceira aula, com as crianças organizadas em uma dupla e um trio, o texto narrativo foi apresentado aos alunos em partes, ou seja, em parágrafos - cada qual transcrito em uma folha sulfite $\mathrm{A}_{4}$, com fonte Arial 48. Cada criança recebeu dois parágrafos do texto. E, novamente, solicitou-se que destacassem as palavras que já conheciam. Depois, foi proposto o desafio de ordenar a sequência de parágrafos, sem qualquer cópia da narrativa como base. Houve dificuldades em ordenar os parágrafos. Este fato mostrou que uma leitura apenas global e superficial do texto é insuficiente para compreender e dar significado a ele, assim sendo, o vocabulário na linguagem escrita não se tornou efetivamente adquirido. Os limites do modelo global de leitura ficam evidenciados ainda quando se pensa que a criança surda 
Alice no País da LIBRAS: uma experiência/reflexão pedagógica de letramento...

precisa trabalhar com o texto em português brasileiro para incorporar a sua sintaxe. Por isso, o trabalho efetivo com a materialidade linguística se torna uma etapa fundamental sempre que permite voltar ao texto como um todo para a checagem de informações e entendimento do seu funcionamento global.

Sendo assim, realizamos novas mediações correspondentes à narrativa em LIBRAS, por meio de ditados de palavras e frases importantes no contexto de crianças surdas. Como exemplo, a sentença: "A Alice caiu no buraco". Assim, tendo como base as palavras-chave, a turma ordenou coletivamente os parágrafos, reconstruindo o texto e elaborando um cartaz vertical.

\section{A INTERPRETAÇÃO}

Para efetivar esta experiência, os alunos receberam os mesmos parágrafos recortados em tamanho menor, sendo que cada aluno tinha todas as partes (parágrafos) do texto para organizá-lo individualmente. Na sequência, foram distribuídas aos alunos atividades de interpretação sobre a narrativa, com a intenção de fazê-los refletir sobre os acontecimentos da história, sobretudo suas causas e efeitos, conforme as questões levantadas na primeira aula, após a história ter sido narrada em LIBRAS.

Numa atividade posterior, foi solicitado que fizessem produção e leitura das frases, com consulta da escrita do vocabulário e auxílio do professor. Os alunos tiveram e apresentaram total autonomia na construção da estrutura lógica das frases, realizando interpretação por meio de desenho e, através desta atividade, começaram a compreender que as imagens mentais, as figuras e os desenhos, bem como os sinais em LIBRAS, podem também ser expressos pela escrita. Ou seja, a escrita também pode representar acontecimentos, pensamentos, mensagens, registros, como qualquer desenho, como qualquer sinal. Isto porque a leitura pela via direta permite a compreensão e a significação, não somente do que está escrito, mas também de desenhos, fotografias, rótulos e até de sinais em LIBRAS, pois o surdo não ouve a mensagem do outro, ele lê o que o outro sinaliza, embora o outro sempre fará a leitura do que o surdo sinaliza. A leitura em si é um processo visual espacial, daí a característica visual espacial da Língua de Sinais.

Assim, nesta etapa do trabalho, diante do estímulo para a leitura interpretativa, os alunos começaram a perceber as relações sintáticas do português brasileiro - 0 que representa um efetivo progresso no processo de aprendizado da leitura pelos alunos surdos. Em atividades anteriores a este projeto, constatava-se que quando 
as crianças ainda não tinham a noção de sintaxe, faziam suas hipóteses, ao encontrarem palavras já conhecidas, para tentar chegar ao sentido do texto. Quando percebem a sintaxe, além das hipóteses, elas começam a fazer conexões entre as palavras e aplicar o que todo bom leitor faz: a antecipação da mensagem com a ajuda justamente da sintaxe.

\section{A PESQUisa}

Foi interessante observar o deslumbramento dos alunos em ler e interpretar, fazendo conexões entre as palavras. Vale considerar que os alunos não possuem vocabulário extenso em português brasileiro, mas foi revelado às crianças que elas podem pesquisar, perguntar e, assim, ler e compreender o sentido das frases e do texto.

Mediante o incentivo à pesquisa e ao estudo de vocabulário, e a partir das informações interpretadas, foram inseridos outros gêneros textuais além do narrativo e foram realizadas conexões e correspondências entre os textos. Assim, iniciamos a etapa de pesquisa deste projeto, sendo trabalhados outros gêneros textuais relacionados à temática. Na aula seguinte, foi realizada a leitura ideovisual da parlenda "Tempo", destacando a palavra-chave TEMPO. Tal leitura foi realizada com eficácia pelos alunos, que começaram a dramatizar em LIBRAS a parlenda. Aproveitando o seu entusiasmo, foi-lhes perguntado: O que é tempo? Com tal pergunta, foi feita uma reflexão sobre tempo passado e tempo futuro, tempo de horas, tempo de mês e ano, e o processo de espera - estimulando os alunos a uma associação lógica sobre períodos, configurando, assim, a orientação temporal.

\section{A PRODUÇÃo}

Em seguida, fez-se a leitura ideovisual do texto $O$ chá das cinco de forma interdisciplinar ao acrescentar conteúdos de matemática, como medidas de tempo, por exemplo. Assim, realizou-se atividade de leitura de horas, produzindo frases descritivas, como, por exemplo, "o chá das seis", enfatizando o período do dia e destacando os verbos INICIAR e TERMINAR. Então, ainda enfatizando o processo e leitura de horas, os alunos pesquisaram e preencheram uma tabela com as atividades e horários correspondentes a sua própria rotina diária, destacando outros verbos como ESTUDAR, ACORDAR, BRINCAR e DORMIR. Após o preenchimento, os alunos transcreveram a tabela de rotina diária em forma de texto descritivo sob o 
Alice no País da LIBRAS: uma experiência/reflexão pedagógica de letramento...

título "Minha rotina". Ressalta-se que, nesta atividade, dois alunos necessitaram de mediação na estruturação lógica das frases, mas se mostraram motivados a realizar o texto - já que a produção ressaltava um fator essencial da identidade, que é a rotina.

Numa aula posterior - ainda na concretização do processo de produção de texto - foi entregue aos alunos uma imagem da menina Alice olhando através da fechadura de uma porta e, ao lado da porta, um espaço em branco. Neste espaço, foi solicitado que os alunos imaginassem o que Alice estava "vendo", o que havia atrás da porta. Alguns alunos, que apresentam um perfil de aprendizagem mais objetivo, representaram o próprio "País das Maravilhas", tendo por referencial a narrativa inicial. Já outros se mostraram mais criativos, optando por representar um lugar diferente, como uma praia. Em atividades como esta é possível explorar a expressão pictórica de cada educando, percebendo qual é seu estilo de aprendizagem e sua interação com o que está vivenciando na sala de aula.

Realizado o desenho, foi proposto que os alunos escrevessem produzindo frases simples, mas que descrevessem o lugar que imaginaram/desenharam - estabelecendo conexão entre sujeito, verbo e objeto. Todos os alunos demonstraram interesse, sendo que alguns, com maior repertório de vocabulário no que corresponde ao português brasileiro escrito, demonstraram maior habilidade na produção, não necessitando de mediação.

Ainda na etapa de produção, numa aula posterior, foi realizada, por meio de multimídia (tablets), a coleta de dados/informações referentes à Lebre e ao Coelho. Os alunos foram divididos em dois grupos: um de pesquisa referente à Lebre e, outro, referente ao Coelho. Eles se mostraram motivados com a pesquisa por utilizar ferramenta de multimídia, demonstrando envolvimento com os dados registrados e realizando leitura funcional. Após a pesquisa, os alunos repassaram em LIBRAS - tanto para a professora como para os demais colegas - os dados que foram registrados na lousa. Constituiu-se, assim, de maneira coletiva, um mapa conceitual que se mostrou efetivo na classificação e organização de ideias e informações referentes à pesquisa. E, partindo deste mapa conceitual, realizamos a produção de um texto coletivo, de gênero informativo, realizando leitura ideovisual e destacando as palavras-chave.

Nesta etapa, foi possível perceber maior autonomia dos educandos em relação à leitura, já que a partir de conexões de ideias, eles demonstravam interpretação sobre o contexto do que leram. E quando algum colega apresentava dificuldade na pesquisa de informações, o outro o auxiliava, mostrando o vocabulário e explicando o sentido 
da palavra na frase, no texto. Nesta etapa de produção, de maneira interdisciplinar, incluindo a área de matemática - relativamente ao conteúdo de medidas de tempo os alunos elaboraram convites para um "chá". Cada aluno escolheu um personagem da história Alice no país das Maravilhas, e então, houve a escolha de um personagem de um dos colegas para que fosse elaborado um convite, delimitando destinatário, data e local de realização do chá. As crianças se mostraram entusiasmadas com esta produção e, inclusive, produziram outros convites. Também já foram personificando um personagem para a próxima etapa deste projeto - que seria a narrativa teatral.

Para concluir esta sequência didática, foi narrada para os alunos a fábula $A$ Lebre e a Tartaruga - a partir da qual as crianças novamente registraram o que interpretaram da história, realizando o desenho sequencial do enredo em quadrinhos. $E$ depois, com o uso de palavras-chave relacionadas à fábula, realizaram um texto coletivo, de gênero narrativo, descrevendo o enredo. Assim, fez-se a leitura ideovisual de tal texto, interpretando as causas e efeitos descritos no enredo e destacando perguntas como: Por que a tartaruga ganhou? Por que o coelho perdeu? - voltando ao processo inicial, a narrativa em LIBRAS. Nesta atividade, foi perceptível o avanço no que corresponde à leitura ideovisual e à assimilação de vocabulário pelos alunos, pois estes não necessitaram de tantas mediações como na etapa inicial. Foi gratificante perceber este avanço e o interesse dos alunos em ler o texto referente à fábula.

\section{A DramatizaÇÃo}

Então chegou-se à etapa final do projeto - a etapa da dramatização. Como os alunos se mostraram envolvidos com a temática da obra de Carroll, inclusive estabelecendo jogos simbólicos e personificando os personagens: Você é a Alice! Eu serei o Gato! Ele é o Chapeleiro. Decidiu-se, junto com a equipe pedagógica e com o apoio dos demais colegas professores, montar uma peça de teatro, realizando filmagem e criando um curta-metragem, de aproximadamente 15 minutos. Com o auxílio da equipe da escola, criamos o cenário para as filmagens e o figurino para os alunos dramatizarem o enredo.

Nesta etapa, foi interessante constatar que os próprios alunos, com os jogos simbólicos em relação à narrativa, foram efetivos construtores do enredo em nossa peça de teatro. Claro que houve mediação e orientação, mas o entusiasmo deles em 
Alice no País da LIBRAS: uma experiência/reflexão pedagógica de letramento...

relação ao projeto e ao mundo fantástico da obra de Lewis Carroll foi significativo para finalizar a tarefa de forma lúdica.

\section{Avaliação}

\section{AprendizAgem}

No processo avaliativo, este projeto de letramento - ambientado na obra de Lewis Carrol Alice no País das Maravilhas - teve como principal objetivo estimular a leitura e o desenvolvimento da escrita em português brasileiro, em uma turma do $3^{\circ}$ ano do Ensino Fundamental de uma escola bilíngue para surdos.

Considerando que a aprendizagem da leitura e da escrita pelos educandos surdos ocorre pela via lexical e sintática, e não pela via fonética, o letramento pela via direta se mostra uma metodologia essencial para os alunos surdos adquirirem a função social da leitura e da escrita em português brasileiro, utilizando a LIBRAS como ferramenta de mediação; daí a modalidade de educação bilíngue. Além disso, "o papel do professor é fundamental na mediação da leitura do texto pelos alunos. É ele que irá construir pontes de significado entre o conhecimento prévio que o aluno traz e o conhecimento veiculado pelo texto" (FERNANDES, 2006, p. 15).

Entretanto, despertar o interesse dos educandos surdos para uma segunda língua - no caso o português brasileiro na modalidade escrita - é um desafio, tanto de ensino quanto de aprendizagem.

(...) Quanto mais uma criança parece estar com dificuldade, mais o pedagogo deve se mostrar atento ao caráter verdadeiramente funcional das situações de aprendizagem, reduzindo sensivelmente as intervenções de ensino que não se justificam. (FOUCAMBERT, 2008, p. 128)

Isto porque a LIBRAS - a língua natural do educando surdo, pela qual ele expressa seu conhecimento de mundo - é uma língua visual espacial. Desta forma, o aluno surdo não buscará apenas usar imagens e gravuras como suporte principal para a leitura, passando a perceber, assim, a funcionalidade da mensagem escrita, considerando os contextos e significados de palavras, frases e textos. Tal fato evidencia que "a língua escrita não é nada mais que uma prática; ela se cria por esta prática e é essa prática 
que se aprende. $O$ que interessa ao pedagogo é saber o que é esta prática, se ele quiser ajudar a criança a adquiri-la (...)" (FOUCAMBERT, 2008, p. 35).

Então, a prática de letramento, ambientada em temáticas que despertam o interesse infantil e mediada pela LIBRAS, tendo como ponto de partida o conhecimento prévio do educando, conduz o aluno surdo a reflexões e significações entre palavras e textos para que ele desenvolva a leitura funcional. Os alunos quando percebem o significado de palavras e fazem conexões entre elas, organizando e classificando dados e informações de um texto, tornam-se entusiasmados com o uso funcional do português brasileiro, curiosos com novos vocabulários e gêneros textuais, e motivados a produzir e a escrever seus próprios textos.

Todo este envolvimento e interesse foi perceptível nos alunos no decorrer das etapas deste projeto. Eles se mostraram curiosos e estimulados a fazer a leitura ideovisual dos textos propostos porque foram instigados a conhecer o fantástico País das Maravilhas, a saber mais sobre os personagens do enredo, a compreender mais sobre lebres e coelhos.

Cada aluno demonstrou um ritmo próprio de leitura, assimilação de vocabulário, interpretação e produção escrita, mas todos se mostraram envolvidos com a temática e interessados pelo português brasileiro na sua forma escrita. Então, considerou-se que o principal objetivo deste projeto - estimular a leitura - foi efetivamente atingido.

Como ferramenta de avaliação, foi realizada a observação dinâmica da interação dos alunos com os conteúdos propostos ao longo da sequência didática, bem como a percepção e o registro da participação dos alunos nas atividades e etapas de tal sequência.

Tais registros estão relacionados ao desenvolvimento das atividades pelos alunos e à realização das produções, tanto coletivas quanto individuais. E, ao final da sequência didática, foi realizada uma atividade para sondagem de aprendizagem relativa aos eixos avaliativos para a área de letramento, tais como: leitura, trabalho com o vocabulário, interpretação, análise linguística e produção escrita.

Sendo assim, neste projeto de letramento, destacou-se o processo de significação que os alunos conquistaram diante dos textos lidos, tendo a língua natural como ferramenta de mediação. Tal projeto mostrou que é possível abordar sequências didáticas com diferentes gêneros textuais e relacionadas às demais áreas do conhecimento, promovendo análise linguística, discriminação visual e o despertar do raciocínio lógico na composição e decomposição do significado de palavras, frases e textos escritos. E, por meio da interpretação, significação e organização de 
Alice no País da LIBRAS: uma experiência/reflexão pedagógica de letramento...

informações, estimulou-se o desenvolvimento da leitura em uma segunda língua, sendo que a leitura condiciona a produção escrita. Desta forma, o educando surdo desenvolve a efetiva função social da leitura e da escrita.

Com relação à avaliação, considera-se que nem todos os alunos obtiveram o mesmo desempenho, tendo sido percebidas diferenças no que corresponde ao nível de leitura e assimilação de vocabulário. Entretanto, os alunos que apresentaram dificuldades buscavam superá-las com interesse, perguntando à professora ou aos demais colegas sobre determinada palavra, determinada frase, e, ainda, buscavam em atividades anteriores - como no texto vertical - referenciais para a produção escrita, o que demostrou envolvimento e comprometimento com o projeto. Além disso, foi gratificante constatar a troca de experiências e saberes entre os alunos diante da temática, sendo as atividades coletivas ferramentas efetivas de aprendizagem. Neste projeto, percebeu-se o quanto os alunos aprenderam uns com os outros, estimulando entre eles o uso funcional da leitura e da escrita.

Por isso, consideramos que esta prática foi significativa e positiva, estimulando e desafiando os alunos a ler e a produzir. E a organização deste projeto em etapas (leitura, interpretação, produção e narrativa), delimitando um processo de aprendizagem, permitiu observar em quais eixos avaliativos os alunos estavam avançando ou, ao contrário, em quais necessitavam de maior mediação.

Sendo o letramento para surdos um processo complexo que envolve uma metodologia bilíngue - articulando contextos e significados entre LIBRAS e português brasileiro e entre português brasileiro e LIBRAS - tal projeto precisa ser contínuo, pois aborda novo vocabulário, promove análises linguísticas, apresenta outros gêneros textuais e amplia a experiência com a produção escrita. Sendo assim, o tempo pedagógico em sala de aula, no que corresponde à prática do letramento, precisa ser efetivamente aproveitado e ampliado, pois há sempre mais a conhecer, a ler. Neste contexto, tal prática possibilitou idealizar novos projetos abordando outros clássicos literários como, por exemplo, Peter Pan, Mágico de Oz, Crônicas de Nárnia e até contos de fadas e fábulas. Tais textos seriam efetivos para ampliar esta prática e promover conexões de saberes e, principalmente, despertar o interesse dos alunos surdos para o mundo da leitura. Na realização deste projeto, foi interessante perceber o entusiasmo da professora ao realizar novas práticas, organizar novas temáticas para estimular a leitura dos alunos e conduzi-los à descoberta da literatura. 


\section{CONSIDERAÇÕES FINAIS}

Como observado neste projeto, baseado no conto Alice no país da Maravilhas, os alunos se mostraram interessados no enredo e, instigados a ler, passaram a buscar informações sobre a temática e os personagens, utilizando a leitura e a escrita de maneira funcional.

Entretanto, realizar uma sequência didática que evidencie e oportunize ao educando uma significação sobre determinado tema exige do educador comprometimento e dedicação para concluir as etapas planejadas. É necessário, sobretudo, instigar os educandos a expressar seu conhecimento de mundo e a usar este conhecimento na contextualização da leitura e na construção da escrita. É preciso escolher os melhores textos de diferentes gêneros, preparar graficamente estes textos, planejar atividades de pesquisa e abordar determinada temática. É também necessário mediar as conexões que os alunos criam diante dos textos lidos, conduzindo-os à lógica da palavra escrita ao estabelecer o seu uso funcional no cotidiano.

É um trabalho complexo, mas torna-se gratificante quando os alunos se interessam pelo contexto da temática e começam a ler, a fazer conexões e a pesquisar informações de forma autônoma.

\section{REFERÊNCIAS}

CARROLL, L. Aventuras de Alice no País das Maravilhas; Através do espelho e o que Alice encontrou por lá. Tradução: Maria Luiza Borges. Rio de Janeiro: Zahar, 2009.

CARVALHO, M. Alfabetizar e letrar: um diálogo entre a teoria e prática. Petrópolis/RJ: Vozes. 2013. FERNANDES, S. Letramento na educação bilíngue para surdos: caminhos para a prática pedagógica.

In: FERNANDES, M. C. L.; MARÇALO, M. J.; MICHELETTI, G. (Org.). A língua portuguesa no mundo. São Paulo: FFLCH, 2008. p. 1-30. Disponível em: <http://simelp.fflch.usp.br/slp27>. Acesso em: 13 nov. 2018.

FERNANDES, S. Letramentos na educação bilíngüe para surdos. In: BERBERIAN, A. P.; MASSI, G.;

ANGELIS, C. M. de. (Org.). Letramento: referenciais em saúde e educação. São Paulo: Plexos, 2006. FOUCAMBERT, J. Modos de ser leitor. Tradução de Lúcia Peixoto Cherem e Suzete Bornatto.

Curitiba: Editora UFPR, 2008.

GUARINELLO, A.C. O. papel do outro na escrita dos sujeitos surdos. São Paulo: Plexos, 2007.

LOPES, M. C. Surdez e Educação. Belo Horizonte: Autêntica, 2007.

QUADROS, R. M.; SCHMIEDT, M. L. P. Ideias para ensinar português para alunos surdos. Brasília: MEC/SEESP, 2006. 
Alice no País da LIBRAS: uma experiência/reflexão pedagógica de letramento...

SILVA, M. P. M. A Construção de sentidos na escrita do aluno surdo. São Paulo: Plexos, 2001. SOARES, M. Letramento: um tema em três gêneros. São Paulo: Autêntica, 1999.

\section{SOBRE AS AUTORAS:}

Lúcia Peixoto Cherem é graduada em Letras Português-Francês (Universidade Federal do Paraná), tem Especialização em Linguística Aplicada (Sorbonne- Paris XIII, França) e Doutorado direto em Língua e Literatura Francesa (Universidade de São Paulo). É professora aposentada da Universidade Federal do Paraná, mas ainda é professora colaboradora da Pós-graduação de Letras da mesma universidade. Tem experiência na área de ensino de línguas estrangeiras, literatura brasileira e aprendizagem da leitura em língua materna, segunda língua, língua estrangeira e em português brasileiro para surdos, com pesquisa em Letramento e Leitura. E-mail: luciacherem@ufpr.br.

Suellym Fernanda Opolz é graduada em Pedagogia (Universidade Federal do Paraná), tem Especialização em Educação Especial (Pontifícia Universidade Católica do Paraná) e Especialização em Psicopedagogia (Pontifícia Universidade Católica do Paraná). Atualmente cursa Mestrado em Educação (Universidade Federal do Paraná). É professora da rede municipal de ensino de São José dos Pinhais/PR. Tem experiência na área de Educação Infantil e séries iniciais do Ensino Fundamental em Educação bilíngue para surdos, com pesquisa em letramento. Atua também como professora mediadora no Curso de Pedagogia Bilíngue (modalidade EaD) do Instituto Nacional de Educação de Surdos. E-mail:suopolz@gmail.com.

Recebido em 07 de abril de 2018 e aprovado em 18 de outubro de 2018. 